\begin{tabular}{l|l|l|l|l} 
Volume 2 & Issue 1 & February (2022) & DOI: $10.47540 /$ ijias.v2i1.439 & Page: $80-87$
\end{tabular}

\title{
Assessment of Awareness on Climate Change among Public and Private Universities of Lahore
}

\author{
Ayesha Mohsin ${ }^{1}$, Abeera Shehzad $^{1}$, Fatima Bilal $^{1}$, Fatima Imran $^{1}$, Sana Akhtar ${ }^{1}$, Syeda Anna \\ Fatima $^{1}$ \\ ${ }^{1}$ Department of Environmental Sciences, Kinnaird College for Women University, Pakistan
}

Corresponding Author: Ayesha Mohsin; Email: ayeshamohsin51@gmail.com

\begin{tabular}{ll}
\hline A R T I C L E I N F O & A B S T R A C T \\
Keywords: Climate Change, Global & As everything in this world evolves or changes, so does our climate. Scientists have \\
Crisis, Tertiary Institutions. & now proved that climate change is happening at a much faster rate than before. \\
& Pakistan is one of the most vulnerable continents to climate change impacts. \\
Received $: 17$ January 2022 & Pakistan is considered as 7th most vulnerable country to climate change. Recently \\
Revised $: 10$ February 2022 & in Lahore, many major events occurred due to climate change like the occurrence of \\
Accepted $: 13$ February 2022 & smog. The present study was conducted in 4 different tertiary institutions of Lahore, \\
& Pakistan. A descriptive survey design was specially employed for this study which \\
& used a stratified random sampling method for selecting the students. Moreover, a \\
& structured questionnaire titled climate change awareness was developed for \\
& collecting data from the students based on their level of awareness. According to \\
& this survey, 49.1\% of the students know about the policies government is making \\
& regarding climate change. 62.5\% of the respondents agreed that they have the \\
& necessary information to prepare for the impacts of climate change. The result of \\
& the findings showed a moderate level of awareness about climate change among the \\
& students. Awareness of climate change is an important ingredient for the successful \\
& implementation of climate change policy in the country. By improving the climate \\
& services and raising awareness about climate change and once it starts to grow it can \\
& be integrated into local, national, and sectoral development plans.
\end{tabular}

\section{INTRODUCTION}

The word Climate refers to the condition of the atmosphere that stays for a long time about 11-40 years. It is a long-term summary of the difference in temperature, atmospheric pressure, wind, humidity, precipitation, etc. As everything in this world evolves or changes, so does our climate. Various studies have now proved that climate change is happening at a much faster rate than before (Indrani et al., 2010). Humans are now exposed to drastic changes of climate change viz. increase in global temperature, rising in sea level, warming of the sea, shorter and warmer winters, increased incidence of severe cyclones and melting of glaciers and many others most frequent extreme climatic events. These changes have many negative effects on humans as well as the natural ecosystem (Nisha et al., 2014).
Local and broad knowledge about climate change is required to formulate mitigation strategies. Many studies have been done on the awareness of climate change among students, educators, farmers, etc. These studies have shown that an emphasis should be done on the basic understanding of the local community/people to make them aware of climate change (Aymeric et al., 2016; Alfonso, 2021).

Pakistan is one of the most vulnerable countries to climatic impacts. According to various researchers and also according to the minister of climate change who claimed that Pakistan is also on the list with other countries that are threatened by climate change. Pakistan is considered as 7 th most vulnerable country to climate change, also in some studies, it has been shown that by the end of the 21st-century temperature of most of the Asian 
countries will not be suitable or comfortable for the people. In the past decade, many of the unexpected events in Pakistan like; floods, droughts, heatwaves, etc have affected the majority of the population (Shahid Z, 2012).

According to the experts, Pakistan had faced around 150 severe weather incidents due to climate change. In the past 20 years, these climatic events include smog in winter, flash floods, landslides, displaced population, forest fires in summer, freaky heat waves, and melting of glaciers. Climatic literature showed us that global warming will affect the cognitive and physical performance of workers and thereby cause a decrease in effective labor supply. Extreme weather conditions i.e. temperature is detrimental to health. Now there is a debate whether climate change is due to anthropogenic activities or it's a series of natural events. About many kinds of research, it can be proved that this change is more due to different human activities (industrial revolution, agricultural practices, and whatnot). All these activities tend to change the global composition of the atmosphere, disturbing the natural cycles resulting in climate change (Qadir M. et al., 2016).

Climate change is a matter of concern and could be catastrophic in the future if not taken seriously today (Gulam M et al., 2018) The possible effects of climate change are less food production because the crop yield is directly dependent on climatic conditions (particularly rainfall patterns and temperature, chances of more strong tropical cyclones, resulting in the alteration of the wind speeds, due to the melting of the glaciers, floods might become more common, Increase in the disease occurrences and alteration in the biological diversity could also be observed (Stern et al., 2014).

To minimize the climate change effects, it is very important to introduce strategies that can easily tackle the situation and reduce future complications. One of the strategies would be to create awareness among people that how their agricultural practices and industrial activities are creating a negative impact on the climate and the second is to introduce climate and climate changes issues in the school prospectus. It is very important to critically analyze the complex global climate changes and the level of awareness among people in this regard. The next generation must be made aware of the drastic changes in the climate so that they can play their part in minimizing the impact (Whetton et al., 1998).

Recently in Lahore, many major events occurred due to climate change like the occurrence of smog in Lahore. The winters also here are becoming very short and the summers usually last for a long time as compared to previous years. In the year 2019, the temperature in summers in Lahore was very high and was recorded at more than 45 degrees on some days. The agricultural cities of Lahore also faced the issue of climate change regarding the distortion of their crops by the hail storm. This indicated the melting of ice caps. Pakistan has also faced the problem of floods in recent years (Khadija et al., 2021).

According to the Pakistan Higher Education Commission report for 2013-14, there are 161 universities in Pakistan, 1,085 degree colleges and over 3 million students are enrolled in grades 13 to 16 in Pakistan (HEC 2013-14). This youth can help in climate change awareness if they are properly enlightening, hence if we want to understand and adapt the problem of climate change effectively, there is a need to understand the level of youth's knowledge (in this study we are talking about students enrolled in the tertiary institution) their perception of climate change and what they think are the causes and effects of climate change and what possible adaptations can be made toward climate change. This can help us in policymaking towards controlling the impacts of climate change in the country (Oruonye et al., 2011).

Progress in the matter of climate perseverance lays heavily on education. This subject itself put up many complexities and involves some factors to be dealt with. One such factor is whether the problem of climate crisis and change really exists. Such a question impacts whether curriculum changes are really required or not. A problem of this nature takes us back to evaluating the education being imparted regarding the existence of this problem. In dealing with it, we need to consider geographical and cultural differences. A survey in which data was gathered from prominent scholars from China, Saudi Arabia, Brazil, Mexico, Germany, and the United States of America elaborated on how climate change has been perceived differently in light of the social context of it. The US withdrawal from Paris Climate Change Agreement, political and economic hindrances to climate movement, reforms in this 
field, and the relation between universities and industry were key to determining how climate change was perceived across the globe. In addition to this, the scholars discussed their views on how climate change should be dealt with. Their suggested approach included the teaching of all forms of scientific knowledge and facts regarding this topic including all complications and variations; teaching them on how they critically evaluate, engage and blend in their existing knowledge across disciplines and nationalities; working in coordination to reach an effective curriculum; establish a better connection and understanding among the student by revolutionizing the teaching methodologies and make them more efficient. The consequences for studying this subject have been elaborate on and argued upon by figures from across the globe. Such perspectives tend to enhance the educational practices to shape a brighter, sustainable future (Krystal et al., 2018).

The atmosphere of disinformation regarding climate could have been mitigated with the right amount of education being imparted among the students about this topic. A study analyzed and assessed how the subject of climate change is being dealt with in the top 100 universities including liberal art colleges in the United States of America. The focus is on the kind of curriculum designed and the percentage of students taking up a course of this nature across schools, the probability of which is calculated to be around 0.17. This record is higher in research institutes, liberal art colleges, social science and science-focused programs, and public universities falling under the legislature designed by Democrats as opposed to Republicans. It has been agreed from analysis of existing data that if authors of climaterelated literature add to how curriculums and course outlines can be designed to integrate climate studies, including both the science and nature of it, will help improve the prevailing conditions. The purpose of the study is to enhance the research on existing literature regarding sustainability and use it to make further research on curriculum advancement (David et al., 2018).

Another study focuses on the level of climate education among the livestock farmers belonging to the Eastern Cape Province of South Africa. It highlighted the factors affecting the adaptation measures and the efficiency of these measures.
Results showed marital status, educational qualifications, formal extensions, and temperatures impacted the degree of awareness regarding climate change. The study also suggested positively influencing factors regarding adjustments can be integrated into these measures and then be implemented (Mandleni et al., 2011).

This study focuses on the level of climate change awareness among students in tertiary institutions in Lahore. The main aim of the study is to raise the level of awareness and to educate young people about climate change. The present study was conducted in 4 different tertiary institutions of Lahore, Pakistan. Lahore is the capital of the Punjab province of Pakistan. It is the second-largest city in Pakistan. Its total population is 10.26 million. There are much reputable public and private tertiary institutes in Lahore. The literacy rate of Lahore is sixty-four percent. Currently, Lahore is facing drastic climate changes.

\section{METHODS}

The study was conducted to examine the level of climate change awareness among the students in the tertiary institute of Lahore. A descriptive survey design was specially employed for this study which used a stratified random sampling method for selecting the students. Moreover, a structured questionnaire titled climate change awareness was developed for collecting data from the students based on their level of awareness. The structured questionnaire was divided into two sections, the first section includes the demographics and the second section involves transition and more complicated questions related to students' perception of climate change and its awareness, its causes, effects, and adaptive measures.

The tertiary institutes in Lahore were stratified based on their administrative structure, the government, and private institutes. Then a total of four institutes was selected, two from the public and two from the government sector for conducting the survey properly and accurately. A total of 801 students was selected, 200 from every three institutes and 201 from the fourth institute. The questionnaire scheduled was randomly administrated to ensure that every student had an equal chance of been selected. The data collected from the questionnaire was through field survey as well as online questionnaire filling. Descriptive 
statistics and frequency were used for the analysis of the data collected. Tables, graphs, and pie charts were formulated for the data presented.

\section{RESULTS AND DISCUSSION}

Without a doubt, climate change is an existing threat not only to human civilization but to the ecosystem as a whole. Through a survey across 119 countries, the influence of social and demographic nuances, geography, perceptions, and beliefs of the public was recorded. It was concluded that education on a massive scale covering the entire global populace is the sole strong determinant of climate change awareness. Decrypting the ties of culture to the climate change crisis is especially the key predictor of climate change perception. This is especially the case in Europe and Latin America.
Abnormal temperature changes are key forecasters in other regions like Asia and Africa. All this delineates how important communication among countries regarding perceptions linked to climate change is important. This connection can be built by improving fundamental education on this matter, increasing climate literacy, enhancing public awareness and engagement (Tien Ming Lee et al., 2010).

The study surveyed the climate change awareness among the students of public and private universities. The study disclosed the degree to which the students of universities in Lahore have information about climate change. The study informed about the level/degree of awareness and curriculum coverage.

Table 1. Demographic information of the respondents.

\begin{tabular}{|l|l|c|c|}
\hline & Response & Frequency & Percentage (\%) \\
\hline Institute & GC & 200 & 25 \\
\hline & LUMS & 200 & 25 \\
\hline & CMH & 200 & 25 \\
\hline & UHE & 201 & 25 \\
\hline Gender & Male & 347 & 43.3 \\
\hline & Female & 454 & 56.7 \\
\hline Age of respondents & $<20$ & 205 & 25.6 \\
\hline & $20-30$ & 427 & 53.3 \\
\hline & $30-40$ & 129 & 16.1 \\
\hline & $>40$ & 40 & 5 \\
\hline Marital Status & Single & 581 & 72.5 \\
\hline & Married & 220 & 27.5 \\
\hline & Total & 801 & 100 \\
\hline
\end{tabular}

Source: Respondents response to questionnaire/survey

The result of the findings shows that $72.3 \%$ of the students interviewed have heard about the term 'climate change', while $27.7 \%$ have not heard about it.

Table 2. Have you ever heard about climate change?

\begin{tabular}{|c|c|c|}
\hline Response & Frequency & Percentage (\%) \\
\hline Yes & 579 & 72.3 \\
\hline No & 222 & 27.7 \\
\hline Total & 801 & 100 \\
\hline
\end{tabular}

Source: Respondents response to questionnaire/ survey

$36.2 \%$ heard the word "climate change" from $\mathrm{TV}, 36.6 \%$ from the internet, $2.1 \%$ from the internet, $16.2 \%$ from books, and $7.5 \%$ from the word of mouth.

Table 3. Which source you heard / use to gain information about climate change?

\begin{tabular}{|c|c|c|}
\hline Response & Frequency & Percentage (\%) \\
\hline TV & 290 & 36.2 \\
\hline Internet & 293 & 36.6 \\
\hline Newspaper & 17 & 2.1 \\
\hline Books & 130 & 16.2 \\
\hline Word of mouth & 60 & 7.5 \\
\hline Research paper & 7 & 0.9 \\
\hline Others & 3 & 0.4 \\
\hline Total & 800 & 100 \\
\hline
\end{tabular}

Source: Respondents response to questionnaire/ survey 
When asked what they know about climate change, $27.2 \%$ of the students responded that it is a weather condition, $63.8 \%$ say it's a change in weather conditions at a particular time while $9 \%$ did not respond to this question. Of the $72.3 \%$ that have heard about climate change, $18.7 \%$ have no idea about what climate change is all about its causes, effects, and possible mitigating measures.

Table 4. What do you know about climate change?

\begin{tabular}{|c|c|c|}
\hline Response & Frequency & $\begin{array}{c}\text { Percentage } \\
(\%)\end{array}$ \\
\hline It is weather condition & 218 & 27.2 \\
\hline $\begin{array}{c}\text { It's a change of } \\
\text { weather at a particular } \\
\text { time }\end{array}$ & 511 & 63.8 \\
\hline Don't know & 72 & 9.0 \\
\hline Total & 801 & 100 \\
\hline
\end{tabular}

Source: Respondents response to questionnaire/ survey

The students do not associate some of the problems related to the change of climates like increase in temperature, flooding, delay in onset, and early cessation of rainfall to it. When asked whether they think the problem of climate change can be solved at all $33.2 \%$ responded in negative while $66.8 \%$ responded in affirmative.

Table 5. Do you think that the problem of climate change can be solved at all?

\begin{tabular}{|c|c|c|}
\hline Response & Frequency & Percentage (\%) \\
\hline Yes & 535 & 66.8 \\
\hline No & 266 & 33.2 \\
\hline Total & 801 & 100 \\
\hline
\end{tabular}

Source: Respondents response to questionnaire/ survey

Many of the students could not help their ignorant but asked how climate change could be controlled by human beings. Their response to the question was clearly demonstrated that seek to know what they think an individual, government, and international organizations can do to solve the problem of climate change. Different shades of opinion were given, while $1.7 \%$ of the students did not respond to this question.

Table 6. How do you think an individual can help to overcome the problem of climate change?

\begin{tabular}{|l|c|c|}
\hline \multicolumn{1}{|c|}{ Response } & Frequency & Percentage (\%) \\
\hline By prayer & 223 & 27.8 \\
\hline $\begin{array}{l}\text { Afforestation and } \\
\text { enlightenment } \\
\text { campaign }\end{array}$ & 456 & 56.9 \\
\hline $\begin{array}{l}\text { Intensify } \\
\text { Research Work }\end{array}$ & 54 & 6.7 \\
\hline $\begin{array}{l}\text { Stop Air } \\
\text { Pollution }\end{array}$ & 54 & 6.7 \\
\hline Don't know & 14 & 1.7 \\
\hline \multicolumn{1}{|c|}{ Total } & 801 & 100 \\
\hline
\end{tabular}

Source: Respondents response to questionnaire/ survey

When asked whether they think the problem of climate change affects them, $79.5 \%$ responded positively, while $20.5 \%$ of the students believed that the problem of climate change does not affect them in any way.

Table 7. Do you think the problem of climate change affects you?

\begin{tabular}{|c|c|c|}
\hline Response & Frequency & Percentage (\%) \\
\hline Yes & 637 & 79.5 \\
\hline No & 164 & 20.5 \\
\hline Total & 801 & 100 \\
\hline
\end{tabular}

Source: Respondents response to questionnaire/ survey

When asked how the problem of climate change affects them, $35.1 \%$ believed it leads to the hotness of the body. $38.7 \%$ believed that climate change causes ill health, $5.2 \%$ believed it leads to the change in environment, $4.9 \%$ believed it causes excessive heating, $5.1 \%$ believed that climate change leads to the reduction in the amount of rainfall, $5.0 \%$ believed that it affects human skin while $6 \%$ believed that it causes the pollution in the environment. 
Table 8. How does the problem of climate change affect you?

\begin{tabular}{|c|c|c|}
\hline Response & Frequency & Percentage $(\%)$ \\
\hline Lead to hotness of body & 281 & 35.1 \\
\hline Lead to changing of the environment & 310 & 38.7 \\
\hline It reduces the amount of rainfall & 42 & 5.2 \\
\hline It causes pollution of the environment & 39 & 4.9 \\
\hline Causes ill health & 41 & 5.1 \\
\hline Excessive heating/high temperature & 40 & 5.0 \\
\hline It affects human skin & 48 & 6.0 \\
\hline Total & 801 & 100 \\
\hline
\end{tabular}

Source: Respondents response to questionnaire/survey

According to the climate change awareness and adaptation by local planning in Punjab (Pakistan), climate change is an additional stress for Pakistan because it imposes threats on the water resources of the country. Local planning officials in Pakistan should play an important role in the adaptation measures and awareness for climate change (Shahid, 2012).

Most of the students believed that climatic Change is causing a change in weather patterns. $23 \%$ believed natural hazards, $7 \%$ diseases, $13 \%$ deforestation, $5 \%$ water pollution, $5 \%$ industrial emission, $2 \%$ rise in sea level, and 3\% do not have any idea about how climate is changing. According to this survey, $49.1 \%$ of the students know about the policies government is making regarding climate change.

Table 9. How do you feel the climate is changing?

\begin{tabular}{|l|c|c|}
\hline \multicolumn{1}{|c|}{ Response } & Frequency & $\begin{array}{c}\text { Percentage } \\
(\%)\end{array}$ \\
\hline $\begin{array}{l}\text { Changing in weather } \\
\text { pattern }\end{array}$ & 340 & 42.4 \\
\hline Natural Hazard & 181 & 22.6 \\
\hline Rise in sea level & 20 & 2.5 \\
\hline Diseases & 60 & 7.5 \\
\hline Deforestation & 100 & 12.5 \\
\hline Water pollution & 40 & 5.0 \\
\hline Industrial emission & 40 & 5.0 \\
\hline Don't know & 20 & 2.5 \\
\hline \multicolumn{1}{|c|}{ Total } & 801 & 100 \\
\hline
\end{tabular}

Source: Respondents response to questionnaire/ survey

$62.5 \%$ of the respondents agreed that they have the necessary information to prepare for the impacts of climate change. When the results were compared with other researches that measure the perception of students of universities about climate change, similar results were found in papers (Oruonye et al. 2011) and (Ezeudu et al. 2016).

The survey was done to know the perception of climate change and risks associated with it by the students of public and private universities in Lahore. The results of the findings showed a moderate level of awareness about climate change among the students. Awareness of climate change is an important ingredient for the successful implementation of climate change policy in the country. By improving the climate services and raising awareness about climate change and once it starts to grow it can be integrated into local, national, and sectoral development plans. It is most important to educate the youth on the impacts of climate change on the country and the importance of adapting to it.

Pakistan is at risk of many disasters related to weather, geophysical, hydrological, and those linked to human activities. The past three decades have witnessed a surge in hydro-meteorological disasters ranging from floods and extreme temperatures to droughts and storms. Efforts have been made by the authorities to educate people on this matter and reforms have been underway to alleviate the devastations of natural calamities. This includes awareness and education on dealing with disaster-prone areas, as discussed in Hyogo Framework for Action (HFA) 2005-2015 (Atta-ulrehman et al., 2014).

National Climate Change Policy 2012 has been made to meet the evolving challenges. This policy emphasizes curricula development that integrates climate-related education in the system all the while making it compulsory. The government has also sent young science students to reputable universities in other countries for higher education to gain a better prospect of the problem and enhance 
creativity when it comes to deriving solutions. Educational Institutes have been provided with financial and technical support to encourage education in this sector. National Disaster Management Plan 2012-2022 highlighted the significance of research in this sector. The policies and plans, if implemented, can alleviate the crisis many folds. The chapter will unfold the nuances of climate change and disaster education, Pakistan's scenario and the situation in this regard, the development of laws and reforms by authorities and institutions, climate change education at secondary and higher education level, technical institutes, National Institute of Disaster Management, Religious Institutes, Community Institutes, State departments and Civil Service Academies (Atta ur Rehman et al., 2014).

\section{ConCLUSION}

This study reveals that there is a moderate level of climatic awareness among university students in Lahore. Many students are aware of the major causes and their effects of climate change. Due to present climatic conditions, it is the need of the hour that universities must establish climate change awareness clubs. Such university clubs will not only identify the challenges but will also help in finding ways to overcome the problems of climate change mitigation and adaptation in their respective areas. Such types of clubs will also help in promoting such awareness through awareness campaigns and tutorials. There is also a need to include studies on the above-mentioned subject as compulsory at educational institutes. Government must start awareness campaigns for the general public to have an emphasis among the same on the causes and adverse impacts of climate change on human health and various types of socioeconomical activities.

\section{REFERENCES}

1. Alfonso, G. P. (2021). Assessing the Climate Change Adaptations of Upland Farmers: A Case of La Trinidad, Benguet, Philippines. Indonesian Journal of Social and Environmental Issues (IJSEI), 2(2), 129-142.

2. Atta-Ur-Rahman, Rajib Shaw. (2014). Disaster and Climate Change Education in Pakistan. Disaster Risk Reduction Approaches in Pakistan. 315-335
3. Aymeric P, Alexandre P, Milena J, Myriam K, Marie LF, and Nicolas G. (2016). Raising Students Awareness to Climate Change: An Illustration with Binding Communication. Environment and behavior. 1-15.

4. B. Mandleni a, F.D.K. Anim. (2011). Climate change awareness and decision on adaptation measures by livestock farmers.

5. David J. Hess B, M. Collins. (2018). Climate change and higher education: Assessing factors that affect curriculum requirements. 170: 14511458.

6. Ezeudu F, Ezeudu S, Sampson M. (2016). Climate change awareness and attitude of senior secondary students in Umuahia Education Zone of Abia State. International Journal of Research in Humanities and Social Studies. 3(3): 7-17.

7. Ghulam M, Ismail AL, Muhammad KB, Mad NS \& Wan MN, Wan D. (2018). Determinants of farmers' awareness of climate change. Applied Environmental Education \& Communication. 1-15.

8. Indrani R. H, Purba H. Ra. (2010). Does awareness to climate change lead to behavioral change. International Journal of Climate Change Strategies and Management. 2(1):6-22.

9. Khadija Gulraiz, Aabgeen Ali. (2021). Expressed Willingness and Awareness of Students towards Climate Change in Lahore, Pakistan. Indonesian Journal of Innovation and Applied Sciences (IJIAS), 1 (3), 219-22.

10. Krystal M. Perkins, Nora Munguia, Rafael Moure-Eraso, Bernd Delakowitz, Biagio. Giannetti, Gengyuan Liu, Mohammad Nurunnabi, Markus Will, Luis Velazquez, (2018). International perspectives on the pedagogy of climate change. Journal of Cleaner Production. (200). 1043-1052.

11. Nesha K, Rahman AA, Hasan K, Ahmed Z. (2014). People's perception in relation to climate change and its adverse effects in Rural Bangladesh. Journal of Environment and Human. 1(3):23-33.

12. Oruonye ED. (2011). An assessment of the level of awareness of the effects of climate change among students of tertiary institutions in Jalingo Metropolis, Taraba State Nigeria. Journal of Geography and Regional Planning. 4(9):513-7. 
13. Pakistan Higher Education Commission report for 2013-14.

https://hec.gov.pk/english/news/HECPublicatio ns/Annual\%20Report\%202013-14.pdf

14. Qadir M, Pir W, Adeel M. (2016). Knowledge, Attitude and Perception about climate change among people of urban area in Attock, Pakistan. International Journal of Agricultural and Environmental Research. 2(4): 333-338.

15. Shahid Z. (2012). Climate change awareness and adaptation by local planning in Punjab, Pakistan. 2012.

https://researchdirect.westernsydney.edu.au/isla ndora/object/uws:17611/datastream/PDF

16. Stern D. I., \& Kaufmann, R. K. (2014). Anthropogenic and natural causes of climate change. Climatic Change. 122(1), 257-269.

17. Tien Ming Lee, Ezra M. Markowitz, Peter D. Howe, Chia-Ying Ko, and Anthony A. Leiserowitz. (2015). Predictors of public climate change awareness and risk perception around the world. Journal of Nature Climate Change. 1014- 1020.

18. Whetton, P. H., Fowler, A. M., Haylock, M. R., \& Pittock, A. B. (1993). Implications of climate change due to the enhanced greenhouse effect on floods and droughts in Australia. Climatic Change. 25(3), 289-317. 